\title{
A controller design method for 3 phase 4 wire grid connected VSI with LCL filter
}

\author{
ANIRBAN GHOSHAL* and VINOD JOHN \\ Department of Electrical Engineering, Indian Institute of Science, Bangalore \\ 560012, India \\ e-mail: ghoshal.anirban@gmail.com
}

MS received 23 March 2014; revised 16 December 2014; accepted 4 April 2015

\begin{abstract}
Closed loop control of a grid connected VSI requires line current control and dc bus voltage control. The closed loop system comprising PR current controller and grid connected VSI with LCL filter is a higher order system. Closed loop control gain expressions are therefore difficult to obtain directly for such systems. In this work a simplified approach has been adopted to find current and voltage controller gain expressions for a 3 phase 4 wire grid connected VSI with LCL filter. The closed loop system considered here utilises PR current controller in natural reference frame and PI controller for dc bus voltage control. Asymptotic frequency response plot and gain bandwidth requirements of the system have been used for current control and voltage controller design. A simplified lower order model, derived for closed loop current control, is used for the dc bus voltage controller design. The adopted design method has been verified through experiments by comparison of the time domain response.
\end{abstract}

Keywords. Grid connected VSI; PR controller; current control; DC bus voltage control.

\section{Introduction}

Control of a grid connected VSI requires regulating the current injected to grid and maintaining dc bus voltage at required level. It involves multiple control loops. In general a two loop controller architecture is followed where current controller serves as the inner loop and the dc bus voltage controller completes the outer loop (Limongi et al 2009; Bao et al 2013; Loh \& Holmes 2005; Prasad et al 2008; Ghosh \& Narayanan 2008). If the circuit configuration is a 3 phase 4 wire whose dc bus midpoint is used for neutral connection, then apart from total dc bus voltage control a common mode control or dc bus balancing controller is also required (Ghosh \& Narayanan 2008; Ghoshal \& John 2011). Primary objective of current control would depend on applications (Limongi et al 2009; Bao et al 2013; Ghosh \& Narayanan 2008). The control

${ }^{*}$ For correspondence 
complexity increases further (Bao et al 2013; Loh \& Holmes 2005) if a higher order filter such as LCL filter is used as an interface between VSI and electric grid to meet harmonic standards.

A popular method of implementing closed loop control of such a system is based on synchronous reference frame (SRF) theory where independent control of active and reactive power can be achieved in ' $d q$ ' frame that is synchronous reference frame (Limongi et al 2009; Bao et al 2013; Loh and Holmes 2005; Prasad et al 2008). In recent times Proportional Resonant (PR) controller has been found as a suitable alternative of ' $d q$ ' frame control (Holmes et al 2009; Zmood \& Holmes 2003; Yuan et al 2002; McGrath et al 2013; Yepes et al 2011). In this method simultaneous control of positive, negative and zero sequence currents can be achieved either in ' $\alpha \beta$ ' stationary reference frame or ' $a b c$ ' natural reference frame (Holmes et al 2009; Zmood \& Holmes 2003; Blaabjerg et al 2006). Literature review shows that during last decade design and tuning of PR controller has been thoroughly researched (Holmes et al 2009; Yepes et al 2010). Tuning of PR controller for current control with ' $L$ ' filter and 'LCL' filter has already been reported (Holmes et al 2009; Yepes et al 2011; Teodorescu et al 2006; Gabe et al 2009). Controller design methods for grid connected VSI with LCL filter along with PR controller are based on either continuous or discrete domain frequency response plots (Limongi et al 2009; Shen et al 2010; Teodorescu et al 2006; Yepes et al 2011) or pole placement by state space analysis (Teodorescu et al 2003; Gabe et al 2009). With present days computing capability it is easy to find desired controller gains from these methods. However, it is difficult to find a closed form equation for the controller gains using these methods because the system under study is a higher order system due to third order LCL filter and second order PR controller. Having closed form expressions for the controller gains can provide design insights.

In this work a simplified control tuning method based on asymptotic bode plots of a 3 phase 4 wire grid connected VSI with LCL filter has been presented. The control architecture involves current control in natural reference frame, differential mode and common mode dc bus voltage control. Using this approximate method, closed form equations for controller gains are obtained based on the inverter parameters. Relevant frequency response plots of the approximate method have been compared with frequency response plots of existing frequency response method to check the validity of the proposed method. Experimental results are also presented for design verification in terms of time domain response behaviour.

\section{System description and control architecture}

Schematics of a $3-\Phi 4$ wire grid connected VSI with LCL filter is shown in figure 1 . This is a split dc bus configuration where the fourth wire or the neutral wire is derived from the midpoint of dc bus capacitance and it is connected to the neutral point of grid. The filter capacitors of LCL filter are star connected and there common point is also connected to neutral. For providing damping to LCL filter resonance, split capacitor configuration for LCL filter as shown in figure 1 has been chosen. The design method for LCL filter with passive damping by split capacitor configuration has been followed from (Channegowda \& John 2010). In the absence of a damping resistor active damping method can also be employed to damp LCL filter resonance (Gabe et al 2009). The parameters of the power converter and LCL filter are given in table 1 . The total filter capacitance is ' $C_{f}=C_{f d}+C_{f f}$ '. The resonance frequency of the LCL filter system is given by $\omega_{\text {res }}=\sqrt{\frac{1}{L_{p} C_{f}}}$ where $L_{p}=\frac{L_{1} L_{2}}{L_{1}+L_{2}}$. The filter resistances $R_{1}$ and $R_{2}$ are $70 \mathrm{~m} \Omega$ each. For experiments related to this work the inverter system shown in figure 1 has been operated as a STATCOM. Use of normalised quantities help to identify the controller gains that lends itself to 


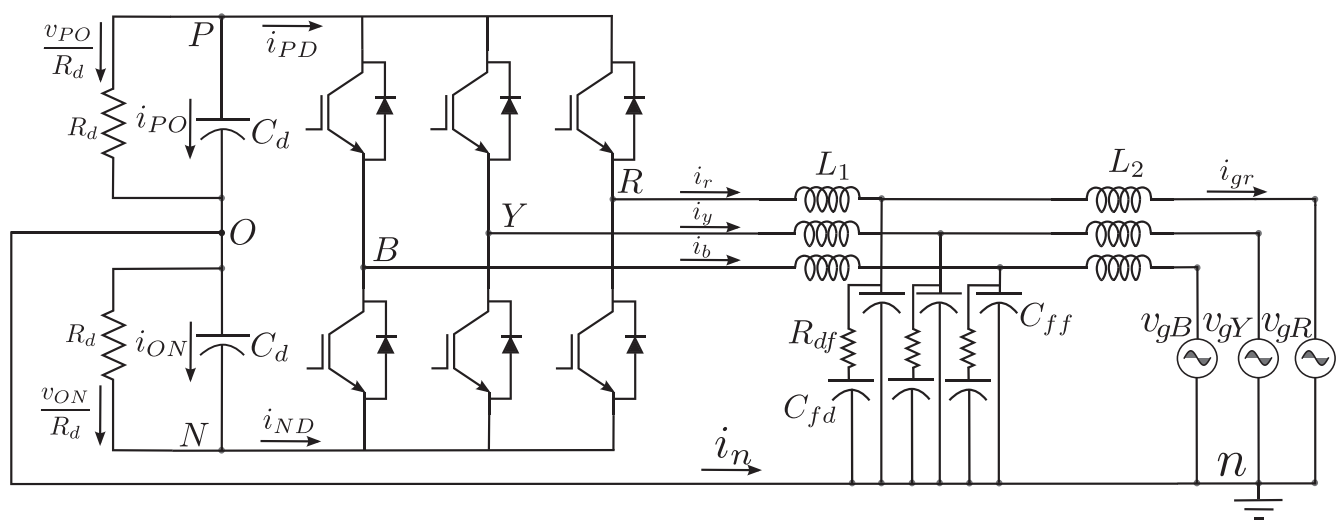

Figure 1. $3-\Phi 4$ wire grid connected VSI with LCL filter for STATCOM operation.

Table 1. System parameters of $3-\Phi 4$ wire grid connected VSI with LCL filter.

\begin{tabular}{lcc}
\hline Parameter & Symbol & Value \\
\hline DC bus & $V_{d c}$ & $300 \mathrm{~V}$ \\
DC bus capacitance & $C_{d}$ & $3300 \mu \mathrm{F}, 500 \mathrm{~V}, \pm 20 \%$ \\
DC bus balancing resistance & $R_{d}$ & $25 \mathrm{k} \Omega, 25 \mathrm{~W}, \pm 10 \%$ \\
Filter inductance & $L_{1}=L_{2}$ & $4.0 \mathrm{mH}$ \\
Filter resistance & $R_{1}=R_{2}$ & $70 \mathrm{~m} \Omega$ \\
Filter capacitances & $C_{f f}=C_{f d}$ & $8.0 \mu \mathrm{F}$ \\
Damping resistance & $R_{d f}$ & $10 \Omega, 25 \mathrm{~W}$ \\
Base voltage & $V_{b}$ & $450 \mathrm{~V}$ \\
Base current & $I_{b}$ & $15 \mathrm{~A}$ \\
Base frequency & $f_{b}$ & $50 \mathrm{~Hz}$ \\
LCL resonance frequency & $f_{r e s}$ & $890 \mathrm{~Hz}$ \\
Current sensor gain & $K_{i}$ & $\frac{1}{15} \mathrm{~V} / \mathrm{A}$ \\
Voltage sensor gain & $K_{v}$ & $\frac{1}{450} \mathrm{~V} / \mathrm{V}$ \\
Switching frequency & $F_{s w}$ & $10 \mathrm{kHz}$ \\
Gain adjustment & $G_{a d j}$ & 3 \\
\hline
\end{tabular}

implementation on digital controller. This is especially useful for fixed point platforms. In the following section controller design aspects for this system are discussed.

\section{PR controller for current control}

Tuning methods of PR controller for grid connected VSI with LCL filter utilise mostly frequency response analysis or discrete domain state space methods (Holmes et al 2009; Teodorescu et al 2006; Yepes et al 2011; Gabe et al 2009). However as number of state variables have increased for this system so the design is relatively complex. In this work, the asymptotic nature of the frequency response plots and desired frequency band around resonant frequency have been utilised 
to find closed form equations for PR controller gains. Here the design of current controller involves selection of the values of $K_{p r}, K_{i r}$ and $\omega_{0}$.

\subsection{Proportional resonant controller}

Proportional Resonant PR) controller is a type of AC controller which is capable of giving very high gain at a desired frequency (Holmes et al 2009; Yepes et al 2011). The ideal ' $s$ ' domain transfer function for realisation of PR controller is given in the following equation:

$$
G_{c}^{P R}(s)=K_{p r}+\frac{s K_{i r}}{s^{2}+\omega_{0}^{2}} .
$$

Here $K_{p r}$ is the proportional gain, $K_{i r}$ is the resonant gain and $\frac{s K_{i r}}{s^{2}+\omega_{0}^{2}}$ is the Resonant Integrator (RI) part. At the resonant frequency, $\omega_{0}$, the transfer function of the RI provides very high gain. The frequency response of both ' $\mathrm{P}$ ' and 'RI' part together is shown in figure 2. Ideally, the PR controller gives very high gain at $\omega_{0}$ and a gain of $K_{p r}$ at all other frequencies. However in reality significant gain could be provided at the vicinity of $\omega_{0}$, shown in figure 2 . The expression for
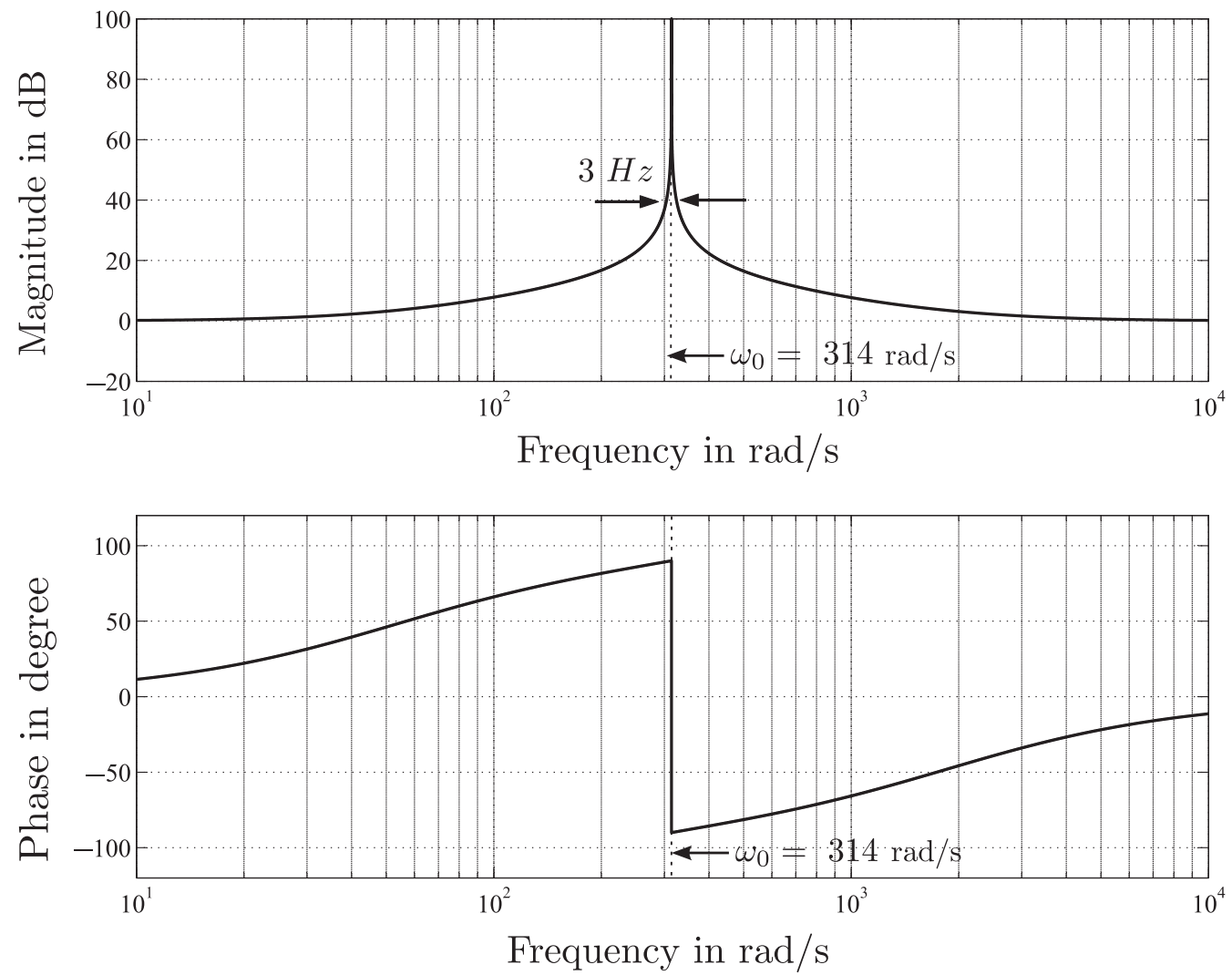

Figure 2. Frequency response of proportional and resonant part together when $K_{p r}=1 K_{i r}=2000$ and $\omega_{0}=314 \mathrm{rad} / \mathrm{s}$. 
PR controller given in (1) can be rewritten as shown in (2). Its phase response at any frequency $\omega$ can be expressed as shown in (3).

$$
\begin{gathered}
G_{c}^{P R}(s)=K_{p r} \frac{s^{2}+s \frac{K_{i r}}{K_{p r}}+\omega_{0}^{2}}{s^{2}+\omega_{0}^{2}} \\
\angle G_{c}^{P R}(j \omega)=\tan ^{-1}\left(\frac{\omega K_{i r}}{K_{p r}\left(\omega_{0}^{2}-\omega^{2}\right)}\right) .
\end{gathered}
$$

From these expressions following observations can be made.

- Different values of $K_{p r}$ would only change the de gain of PR controller for a constant $\frac{K_{i r}}{K_{p r}}$.

- Phase response will remain unchanged if a constant $\frac{K_{i r}}{K_{p r}}$ is maintained for different values of $K_{p r}$.

- The ratio $\frac{K_{i r}}{K_{p r}}$ determines the band around resonance frequency $\omega_{0}$ for which a minimum level of gain can always be provided. As an example, figure 2 shows that for the selected gain values around $\omega_{0}$ a region of width $3 \mathrm{~Hz}$ would have gain of minimum $40 \mathrm{~dB}$.

The transfer function of the RI chosen here, shown in (1), has zero damping or it is an ideal resonator (Yepes et al 2010). In several works instead of choosing (1), a transfer function with extra damping term for RI is used (Holmes et al 2009; Yuan et al 2002; Harnefors 2009). The reason shown for this choice is to limit the infinite gain due to concerns of instability (Holmes et al 2009; Harnefors 2009). However (Yepes et al 2010; Yepes et al 2011) show that the ideal transfer function of RI can be utilised while ensuring stability. In this work the ideal transfer function model of RI has been utilised.

\subsection{System model and frequency response}

The single phase equivalent block diagram structure of closed loop current control in stationary 'abc' reference frame for the system of figure 1 is given in figure 3 . The current controller transfer function $G_{c}^{P R}$ is given by (1). Here system switching frequency is $f_{s w}$ and switching period $T_{s w}=\frac{1}{f_{s w}}$. As double sampling has been utilised so sampling period $T=\frac{T_{s w}}{2}$. The inverter can be modelled as a gain with delay (Holmes et al 2009) as given by $G_{i}=\frac{V_{d c}}{2} e^{-s T_{d i}}$. Where $T_{d i}$, the equivalent inverter delay, can be written as $T_{d i}=1.5 T$ (Holmes et al 2009). The current sensor gain is related to base current by $K_{i}=\frac{1}{I_{b}}$. The term $G_{a d j}$ shown in figure 3 is a gain

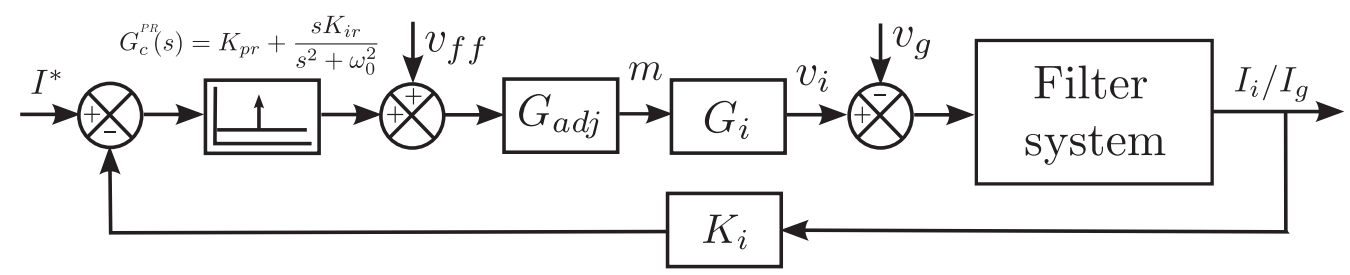

Figure 3. Closed loop single phase equivalent block diagram structure of PR controller based current controlled VSI with LCL filter. 
term for changing base voltage to $\frac{V_{d c}}{2}$ and it can be expressed as $G_{a d j}=\frac{V_{b}}{V_{d c} / 2}$. To reduce output magnitude from the controller a feed forward term $v_{f f}$ is added with controller output. This term can be grid voltage or capacitor voltage of the respective phases (Prasad et al 2008; Holmes et al 2009). If $v_{f f}$ is chosen as zero then the full value of modulation index $(m)$ is generated by current controller. Here $v_{f f}$ has been chosen as the grid voltage.

The current controlled inverter system can be implemented by utilising either inverter current $I_{i}$ or grid current $I_{g}$ as suggested in different literatures (Loh \& Holmes 2005; Shen et al 2010; Tang et al 2012). For both these cases knowledge of the transfer functions $\frac{I_{g}(s)}{V_{i}(s)}$ and $\frac{I_{i}(s)}{V_{i}(s)}$ is of importance.

$$
\begin{aligned}
\frac{I_{g}(s)}{V_{i}(s)} & =\frac{G_{1} G_{2} G_{3}}{1+G_{1} G_{3}+G_{2} G_{3}} \\
\frac{I_{i}(s)}{V_{i}(s)} & =\frac{G_{1}\left(1+G_{2} G_{3}\right)}{1+G_{1} G_{3}+G_{2} G_{3}} \\
\text { where } G_{1} & =\frac{1}{R_{1}+s L_{1}}, G_{2}=\frac{1}{R_{2}+s L_{2}} \\
\text { and } G_{3} & =\frac{1+s R_{d f} C_{f d}}{s\left(C_{f d}+C_{f f}\right)+s^{2} R_{d f} C_{f d} C_{f f}} .
\end{aligned}
$$

The 's' domain expressions of transfer functions $\frac{I_{g}(s)}{V_{i}(s)}$ and $\frac{I_{i}(s)}{V_{i}(s)}$ are given in (4) and (5). Here $G_{1}$, $G_{2}$ and $G_{3}$ are the individual transfer functions of the inductive and capacitive branches. The frequency response plots of $\frac{I_{g}(s)}{V_{i}(s)}$ and $\frac{I_{i}(s)}{V_{i}(s)}$ are shown in figure 4(a) and figure 4(b) respectively. In figure 4 these frequency response plots are indicated as 'With damping' because of non-zero
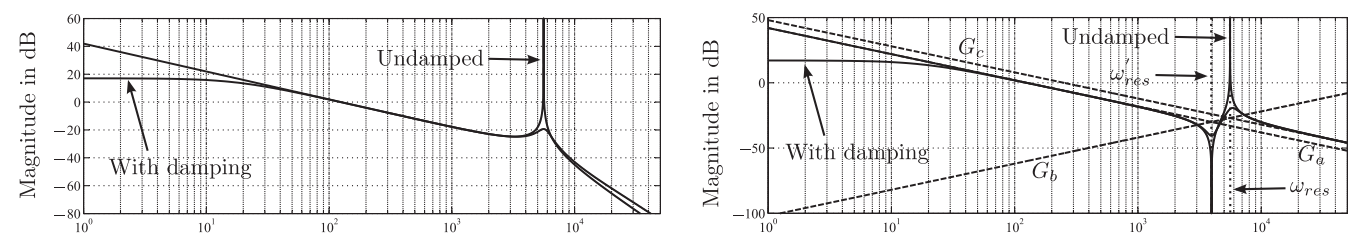

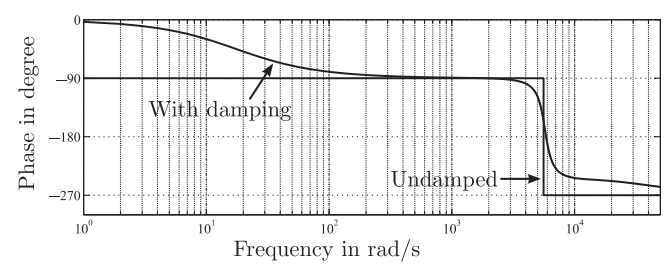

(a)

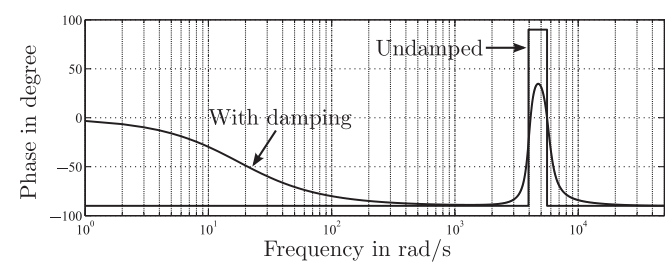

(b)

Figure 4. Frequency response plots of the transfer functions (a) $\frac{I_{g}(s)}{V_{i}(s)}$ and (b) $\frac{I_{i}(s)}{V_{i}(s)}$ of LCL filter with and without damping effects. 
values of $R_{d f}, R_{1}$ and $R_{2}$. The transfer functions of $\frac{I_{g}(s)}{V_{i}(s)}$ and $\frac{I_{i}(s)}{V_{i}(s)}$ with no damping effect are given in (6) and (7) respectively. Here the consideration is that $R_{d f}, R_{1}$ and $R_{2}$ are zero.

$$
\begin{gathered}
\frac{I_{g}(s)}{V_{i}(s)}=\frac{1}{s\left(L_{1}+L_{2}\right)} \times \frac{1}{1+s^{2} L_{p} C_{f}} \\
\frac{I_{i}(s)}{V_{i}(s)}=\frac{1}{s\left(L_{1}+L_{2}\right)}\left(\frac{1+s^{2} L_{2} C_{f}}{1+s^{2} L_{p} C_{f}}\right)=\frac{1}{\frac{s}{\omega_{a}}} \frac{1+\left(\frac{s}{\omega_{r e s}^{\prime}}\right)^{2}}{1+\left(\frac{s}{\omega_{r e s}}\right)^{2}} .
\end{gathered}
$$

Here $\omega_{a}=\frac{1}{L_{1}+L_{2}}, \omega_{r e s}^{\prime}=\sqrt{\frac{1}{L_{2} C_{f}}}, \omega_{\text {res }}=\sqrt{\frac{1}{L_{p} C_{f}}}$ and $L_{p}=\frac{L_{1} L_{2}}{L_{1}+L_{2}}$. Frequency response plots of $\frac{I_{g}(s)}{V_{i}(s)}$ and $\frac{I_{i}(s)}{V_{i}(s)}$ without damping effects are also shown in figure 4. For undamped case frequency response plots of $\frac{I_{g}(s)}{V_{i}(s)}$ and $\frac{I_{i}(s)}{V_{i}(s)}$ have been plotted using (6) and (7). From frequency response plots of figure 4 it can be observed that $\frac{I_{g}(s)}{V_{i}(s)}$ has a greater phase lag after resonance frequency compared to $\frac{I_{i}(s)}{V_{i}(s)}$. The magnitude plot of $\frac{I_{g}(s)}{V_{i}(s)}$ has a slope of $-60 \mathrm{~dB} / \mathrm{dec}$ after resonance frequency, whereas the magnitude plot of $\frac{I_{i}(s)}{V_{i}(s)}$ has a slope of $-20 \mathrm{~dB} / \mathrm{dec}$. Therefore while designing a closed loop controller, the gain cross over frequency can be placed beyond $\omega_{\text {res }}$ if inverter current $I_{i}$ is used as the feedback signal for current loop. If grid current $I_{g}$ is sensed the gain crossover frequency has to be lower than resonance frequency of the LCL filter to avoid instability. Hence if inverter current alone is used as feedback signal for current loop then higher bandwidth can be achieved compared to the situation where grid current alone is used as feedback signal. Also, inverter current would typically be sensed to provide protection to the semiconductor devices (Blaabjerg \& Pedersen 1997). In addition if grid currents are also sensed then the number of sensor would increase. For these reasons inverter current has been utilised as the feedback signal for current loop in this study. The expression of loop gain $G H(s)$ for the system of figure 3 is given in the following equation:

$$
G H(s)=G_{a d j} \times K_{i} \times K_{p r} \frac{s^{2}+s \frac{K_{i r}}{K_{p r}}+\omega_{0}^{2}}{s^{2}+\omega_{0}^{2}} \times \frac{V_{d c}}{2} e^{-s T_{d i}} \times \frac{1}{\frac{s}{\omega_{a}}} \frac{1+\left(\frac{s}{\omega_{r e s}^{\prime}}\right)^{2}}{1+\left(\frac{s}{\omega_{\text {res }}}\right)^{2}} .
$$

Using calculated values of $K_{p r}$ and $K_{i r}$ a verification of the available phase margin through frequency response plot of $G H(s)$ is performed to ensure stability.

The frequency response plots of $\frac{I_{i}(s)}{V_{i}(s)}$ can be approximated by the asymptotes $G_{a}, G_{b}$ and $G_{c}$ as shown in figure 4(b). These asymptotes are further elaborated in figure 5. Here $G_{a}$ and $G_{c}$ have slopes of $-20 \mathrm{~dB} / \mathrm{dec}$. Whereas $G_{b}$ has a slope of $+20 \mathrm{~dB} / \mathrm{dec}$. Asymptote $G_{a}$ can be written as $\frac{1}{s\left(L_{1}+L_{2}\right)}$ by observing expression of $\frac{I_{i}(s)}{V_{i}(s)}$ in (7). Asymptote $G_{a}$ has zero crossing at $\omega_{a}=\frac{1}{L_{1}+L_{2}}$. The points where the two asymptotes $G_{b}$ and $G_{c}$ cross the $0 \mathrm{~dB}$ line are $\omega_{b}$ and $\omega_{c}$, respectively, as indicated in figure 5. These asymptotes are used to find an expression for $K_{p r}$ to achieve desired gain crossover frequency, $\omega_{c r}$, for the closed loop system shown in figure 3 .

\subsection{Design equations}

From figure 5 it can be observed that $G_{a}=\frac{\omega_{a}}{s}$ and $G_{b}=\frac{s}{\omega_{b}}$ have same gain at $s=j \omega_{\text {res }}^{\prime}$. Similarly $G_{c}=\frac{\omega_{c}}{s}$ and $G_{b}=\frac{s}{\omega_{b}}$ have same gain at $s=j \omega_{\text {res }}$. Equating magnitudes of 


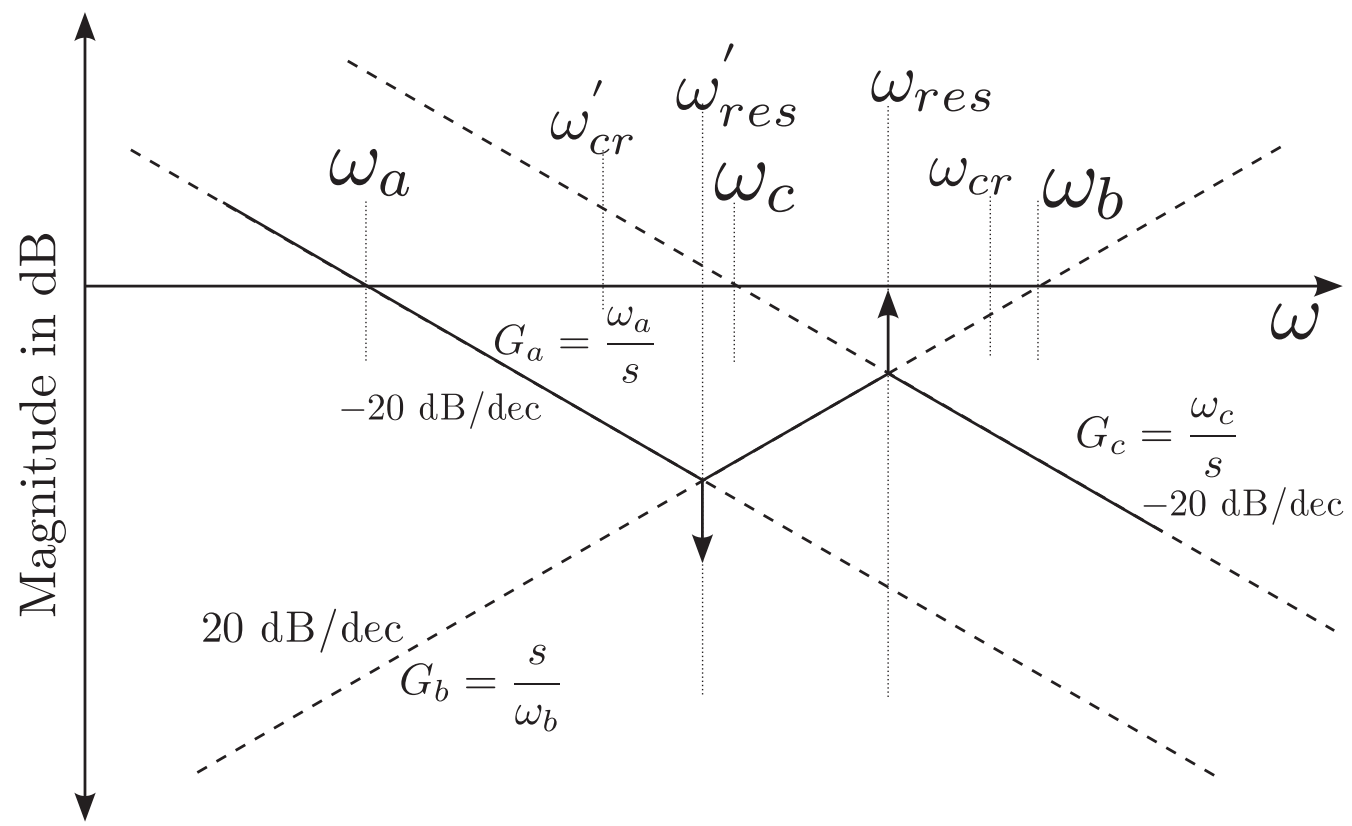

Figure 5. Asymptotic frequency response plots of the transfer function $\frac{I_{i}(s)}{V_{i}(s)}$ of LCL filter.

$G_{a}$ and $G_{b}$ at $s=j \omega_{\text {res }}^{\prime}$ and $G_{c}$ and $G_{b}$ at $s=j \omega_{\text {res }}$ give the expressions of the following equation:

$$
\omega_{a} \times \omega_{b}=\left(\omega_{r e s}^{\prime}\right)^{2} \quad \text { and } \quad \omega_{b} \times \omega_{c}=\left(\omega_{\text {res }}\right)^{2} .
$$

A relation between $\omega_{a}$ and $\omega_{c}$ can be derived from the equations of (9) and using expressions of $\omega_{\text {res }}^{\prime}$ and $\omega_{\text {res }}$, given in (7), $\omega_{c}$ can be expressed in terms of system parameters. These expressions are shown in the following equation

$$
\omega_{c}=\left(\frac{\omega_{\text {res }}}{\omega_{\text {res }}^{\prime}}\right)^{2} \times \omega_{a}=\frac{1}{L_{1}} .
$$

Let the desired gain crossover frequency of $G H(s)$ be chosen as $\omega_{c r}$, where $\omega_{c r}>\omega_{\text {res }}$. Then from expression of $G H(s)$, shown in (8), and figure 5 it can be said that the gain $\left(K_{p r} G_{a d j} \frac{V_{d c}}{2} K_{i}\right)$ changes the crossover frequency of $G_{c}$ to $\omega_{c r}$ from $\omega_{c}$. Now $K_{p r}$ can be calculated by equating the product of $\left|G_{c}\left(j \omega_{c r}\right)\right|$ and $\left(K_{p r} G_{a d j} \frac{V_{d c}}{2} K_{i}\right)$ to 1 .

$$
K_{p r}=\omega_{c r} \times \frac{2 L_{1}}{G_{a d j} V_{d c} K_{i}} .
$$

The expression to calculate $K_{p r}$ is shown in (11). Due to this selection asymptote $G_{a}$ would have a new crossover frequency, termed here as $\omega_{c r}^{\prime}$. Also, asymptote $G_{b}$ would be having a crossover frequency. Hence the closed loop gain would have three crossover frequencies in total. This situation arises due to the choice of selecting crossover frequency $\omega_{c r}>\omega_{\text {res }}$. The crossover 
frequency $\omega_{c r}^{\prime}$ can be found out by equating $\mid G_{a}\left(j \omega_{c r}^{\prime} \mid\right.$ to $\left(K_{p r} G_{a d j} \frac{V_{d c}}{2} K_{i}\right)$. The expression for $\omega_{c r}^{\prime}$ is shown in the following equation

$$
\omega_{c r}^{\prime}=K_{p r} G_{a d j} \frac{V_{d c}}{2} K_{i} \omega_{a}=\frac{K_{p r} G_{a d j} V_{d c} K_{i}}{2\left(L_{1}+L_{2}\right)} .
$$

The values of crossover frequencies $\omega_{c r}$ and $\omega_{c r}^{\prime}$ are used to find an approximated second order system for the closed loop current controller which could be utilised for dc bus voltage controller design (Engelberg 2005).

For selection of $K_{i r}$ it is assumed that a band of $\pm \Delta \omega_{0} \mathrm{rad} / \mathrm{s}$ around the resonance frequency of PR controller $\omega_{0}$ always give a gain of $K$ for the transfer function of PR controller given in (2). The gain of PR controller at $s=j\left(\omega_{0}-\Delta \omega_{0}\right)$ can be equated to $K$ and the resulting relation is shown in the following equation

$$
|K|=\left|K_{p r}\left(1+j \frac{\omega_{0}-\Delta \omega_{0}}{2 \omega_{0} \Delta \omega_{0}-\Delta \omega_{0}^{2}} \times \frac{K_{i r}}{K_{p r}}\right)\right| .
$$

An expression for $K_{i r}$, shown in (14), is obtained after rearrangement of (13) and with the assumption that $\frac{\Delta \omega_{0}}{\omega_{0}} \ll 1$.

$$
K_{i r}=\Delta \omega_{0} \frac{2-\frac{\Delta \omega_{0}}{\omega_{0}}}{1-\frac{\Delta \omega_{0}}{\omega_{0}}} \sqrt{K^{2}-K_{p r}^{2}} \simeq 2 \Delta \omega_{0} \sqrt{K^{2}-K_{p r}^{2}} .
$$

It can be observed from figure 4(b) that the phase of $\frac{I_{i}(s)}{V_{i}(s)}$ for $\omega>\omega_{\text {res }}$ is nearly $-90^{\circ}$. The phase of inverter model $G_{i}$ at any frequency $\omega$ is given by $\angle G_{i}(j \omega)=-\omega T_{d i} \frac{180}{\pi} \mathrm{deg}$. The expression for phase margin $(P M)$ at $\omega_{c r}$ is given in the following equations

$$
P M=180^{\circ}+\left(\angle G_{c}^{P R}\left(j \omega_{c r}\right)+\angle G_{i}\left(j \omega_{c r}\right)-90^{\circ}\right) .
$$

The frequency response plot of closed loop transfer function of the current loop, termed $G_{c l}^{c c}$ and shown in (16), can be found out using forward path and loop gain of the block diagram structure of figure 3 .

$$
G_{c l}^{c c}=\frac{1}{K_{i}} \frac{G H(s)}{1+G H(s)} .
$$

As the current loop has a gain of $K_{i}$ in its feedback path, shown in figure 3, so its low frequency gain under closed loop condition would be $\frac{1}{K_{i}}$. An approximate representation of the frequency response of transfer function $G_{c l}^{c c}$ can be created by utilising gain $\frac{1}{K_{i}}$ and two first order systems with corner frequencies at $\omega_{c r}$ and $\omega_{c r}^{\prime}$. The approximate representation $G_{c l}^{c c a}$ of the closed loop transfer function of current loop is given in the following equation

$$
G_{c l}^{c c a}=\frac{1}{K_{i}} \times \frac{1}{1+\frac{s}{\omega_{c r}}} \times \frac{1}{1+\frac{s}{\omega_{c r}^{\prime}}} .
$$

This approximation is verified by comparison of frequency response plots of $G_{c l}^{c c}$ and $G_{c l}^{c c a}$ in the next section with the help of an example design. 
As this system has multiple gain crossover frequencies, the phase margin that is critical for system stability is at the largest crossover frequency, $\omega_{c r}$. Whereas the closed loop system response such as settling time would be significantly dominated by the lowest crossover frequency $\omega_{c r}^{\prime}$.

From (11) it can be observed that the crossover frequency $\omega_{c r}$, strongly related to system stability, is related to inverter side inductor $L_{1}$ but not on grid side inductor $L_{2}$. So $\omega_{c r}$ is not significantly influenced due to the presence of grid inductance.

However, the crossover frequency $\omega_{c r}^{\prime}$, associated with system response, is dependent on total inductance $L_{1}+L_{2}$ as can be observed from (12). So change in grid inductance will influence the overall system response such as settling time.

It can also be understood that if grid current control is chosen instead of inverter current control then value of $K_{p r}$ can be calculated using (11) but instead of $L_{1}$ the total inductance value $L_{1}+L_{2}$ has to be used and a lower value of $\omega_{c r}$ need to be selected below the filter resonant frequency.

\subsection{Design example}

A step by step method of designing the current controller gains and an example design are given below.

- For the chosen system there are three gain crossover frequencies. Selection of $\omega_{c r}$ for the transfer function $G H(s)$ is important because available phase margin at this point decides system stability. Assuming $\omega_{c r}=2 \pi f_{c r}$, cross over frequency could be selected as $f_{c r}=$ $\frac{f_{s w}}{10}$. This thumb rule selection of $\omega_{c r}$ is to minimize influence of system delay on stability. However to achieve faster response a higher value could also be chosen but stability of the system should be ensured. As an example design, for a system with $f_{s w}=10 \mathrm{kHz}$ a crossover frequency of $f_{c r}=1.5 \mathrm{kHz}$ is chosen here.

- Based on the chosen value of $\omega_{c r}$ a value of $K_{p r}$ can be calculated using (11) and table 1 . For the selected system $K_{p r}=1.26$. From designed value of $K_{p r}$ and using (12), value of $\omega_{c r}^{\prime}$ can be calculated. In this case $\omega_{c r}^{\prime}=4725 \mathrm{rad} / \mathrm{s}$.

- To calculate $K_{i r}$ a frequency band $\Delta \omega_{0}$ and gain $K$ have to be selected. Using these values and (14) $K_{i r}$ can be calculated. Here a frequency band equivalent to $\pm 0.8 \mathrm{~Hz}$ and resonance frequency of $50 \mathrm{~Hz}$ for PR controller is selected. Minimum gain for $\pm 0.8 \mathrm{~Hz}$ around $\omega_{0}$ is selected as $K=100$. The value obtained for $K_{i r}$ is 1005 using (14).

- Phase margin (PM) at $\omega_{c r}$ can be estimated using (15) which is $P M=44.7^{\circ}$.

- With the designed values of $K_{p r}$ and $K_{i r}$, the expression for $G H(s)$, given by (8), is plotted in frequency domain to confirm stability of the system by verifying phase margin (PM) at the furthest $0 \mathrm{~dB}$ crossing. Also values of $\omega_{c r}$ and $\omega_{c r}^{\prime}$ should be verified with designed values. For the present design the furthest gain crossover frequency, that is $\omega_{c r}$ obtained from frequency response plot of $G H(s)$, shown in figure 6 , is at $1.78 \mathrm{kHz}$. The observed phase margin from figure 6 is nearly $45^{\circ}$ which is sufficient for closed loop operation. The value of $\omega_{c r}^{\prime}$ from figure 6 can be observed as $3000 \mathrm{rad} / \mathrm{s}$. The reason for this variation in values of $\omega_{c r}$ and $\omega_{c r}^{\prime}$ is due to the approximations made on a higher order system. The calculated values of parameters of the current controller are tabulated in table 2.

- Frequency response plots of closed loop transfer function of current loop $G_{c l}^{c c}$ and $G_{c l}^{c c a}$ are shown in figure 7. Using values of $K_{i}, \omega_{c r}$ and $\omega_{c r}^{\prime}$ the frequency response of approximated transfer function $G_{c l}^{c c a}$ can be plotted. It can be observed from figure 7 that the frequency 


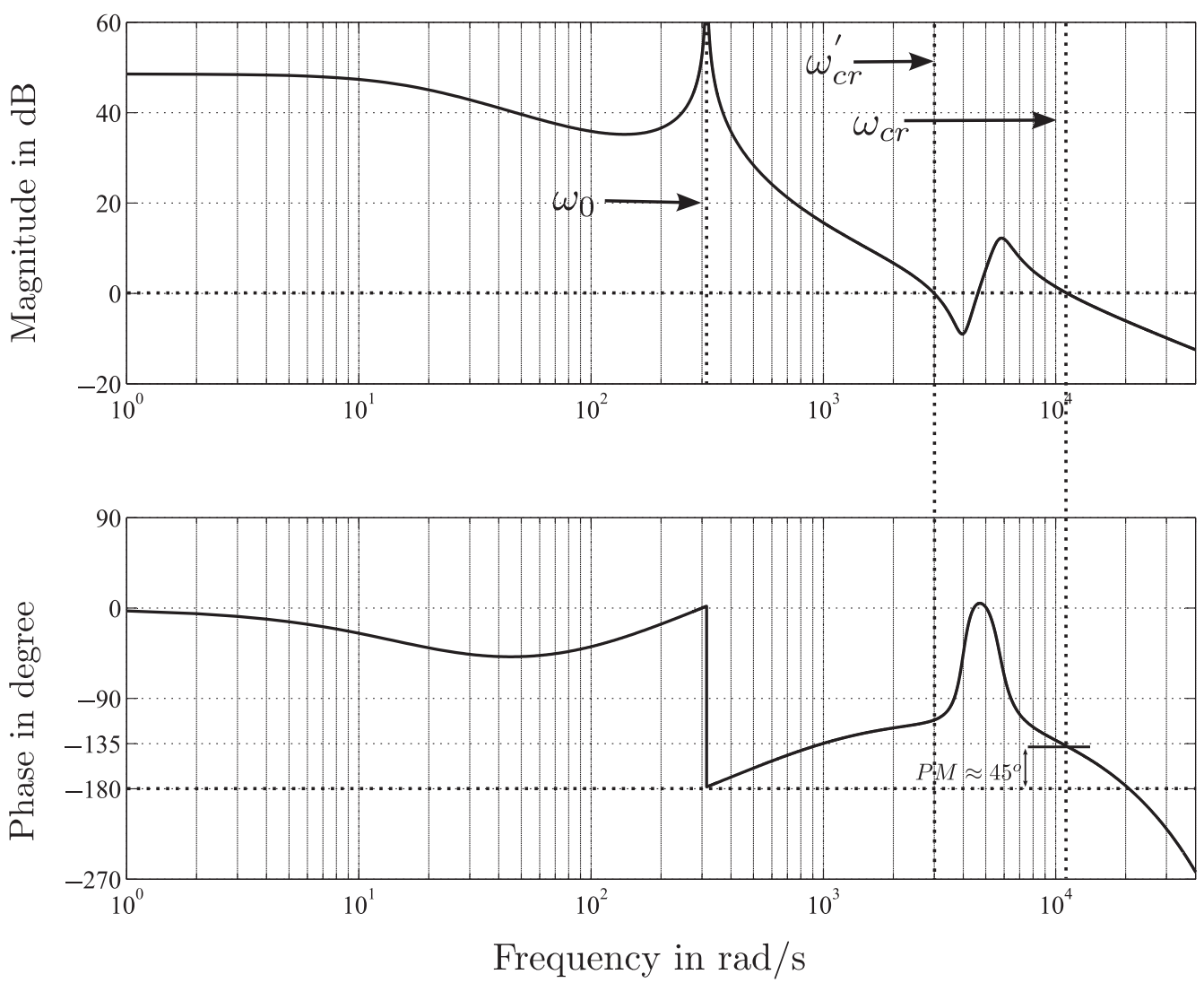

Figure 6. Frequency response plot of loop gain $G H(s)$ for the system shown in figure 3.

responses are equivalent in the low frequency region, which would be the region of interest for voltage controller design. However it also indicates that the response of $G_{c l}^{c c a}$ would be dominated by $\omega_{c r}^{\prime}$ as it decides the slowest of the two poles of $G_{c l}^{c c a}$. Hence settling time for this system can be estimated from $\omega_{c r}^{\prime}$. Settling time for this system can be calculated by use of $2 \%$ criteria (Engelberg 2005). The settling time for the current loop can be estimated as $\tau_{c c}=\frac{4}{\omega_{c r}^{\prime}}$ assuming $\omega_{c r}^{\prime}$ to have a dominant effect on system response. For the present design $\tau_{c c}=1.33 \mathrm{~ms}$.

The simplified method for design of the PR controller provides a bound for the stability and the expected response time of the PR current controlled VSI with LCL filter.

Table 2. Parameters and gains related to current controller.

\begin{tabular}{lccc}
\hline Parameter & Value & Parameter & Value \\
\hline Designed $\omega_{c r}$ & $1.5 \mathrm{kHz}$ & $\omega_{c r}$ from GH(s) & $1.78 \mathrm{kHz}$ \\
Designed $\omega_{c r}^{\prime}$ & $752 \mathrm{~Hz}$ & $\omega_{c r}$ from GH(s) & $477 \mathrm{~Hz}$ \\
$K_{p r}$ & 1.26 & $K_{i r}$ & 1005 \\
\hline
\end{tabular}



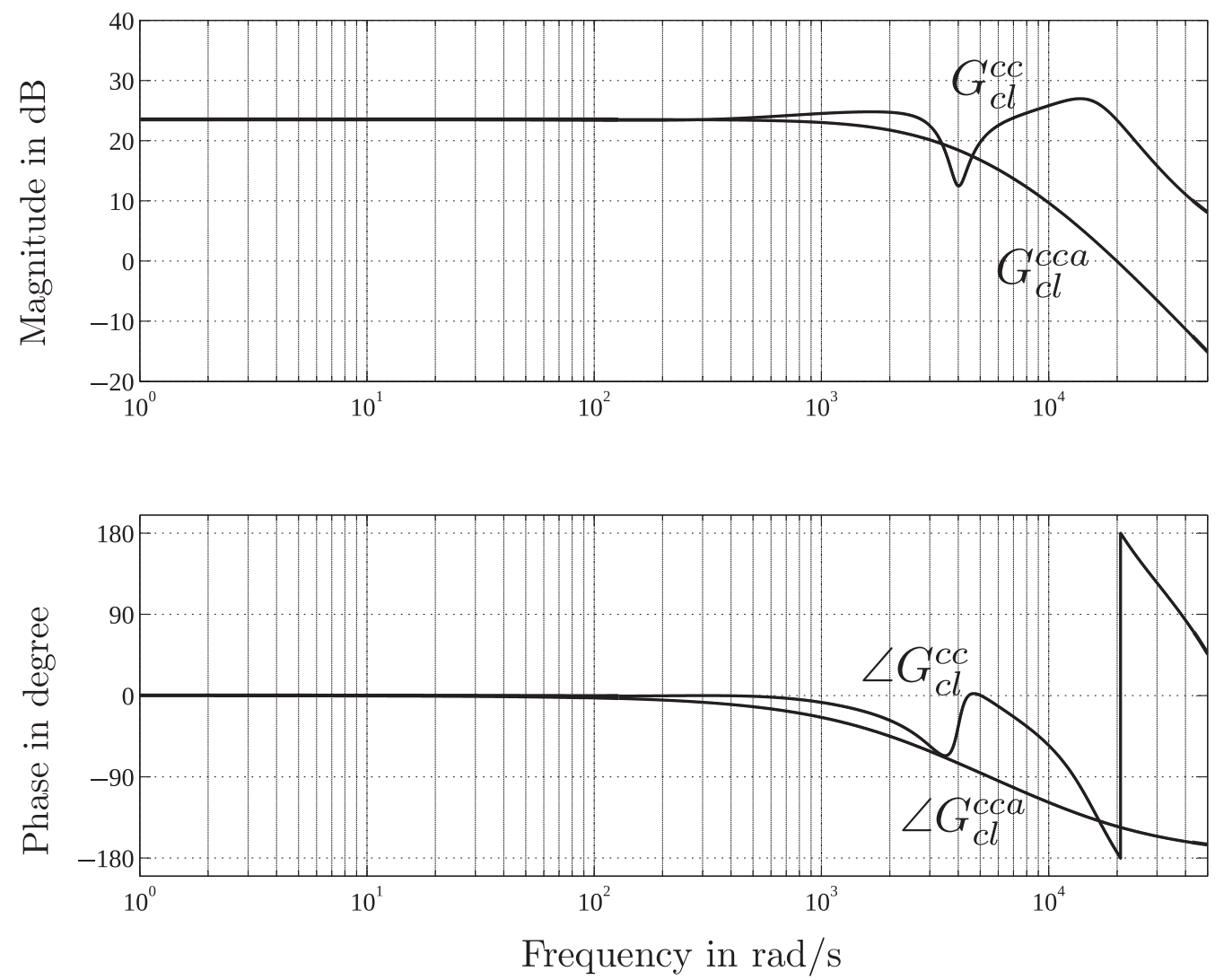

Figure 7. Frequency response plots of closed loop transfer function model $G_{c l}^{c c}$ of current loop and its approximated transfer function model $G_{c l}^{c c a}$.

\subsection{Reference current generation}

In an actual system the reference current $i^{*}$ shown in figure 3 is replaced by individual reference currents for every phase and they are $i_{r}^{*}, i_{y}^{*}$ and $i_{b}^{*}$. These three reference currents are in stationary ' $a b c$ ' reference frame and are generated from $i_{d}^{*}$ and $i_{q}^{*}$ which are reference currents in synchronously rotating reference frame (SRF) and shown in figure 8(b). Here $i_{d}^{*}$ is responsible for reactive power exchange. Whereas $i_{q}^{*}$ is the current reference related to active power exchange and is generated by dc bus voltage controller. In this work the reference current $i_{d}^{*}$ has been chosen as a constant value considering that the VSI is operating as STATCOM with fixed reactive current reference.

\section{DC bus voltage control}

A frequency domain model for the closed loop controller design to regulate dc bus voltage is given below. 


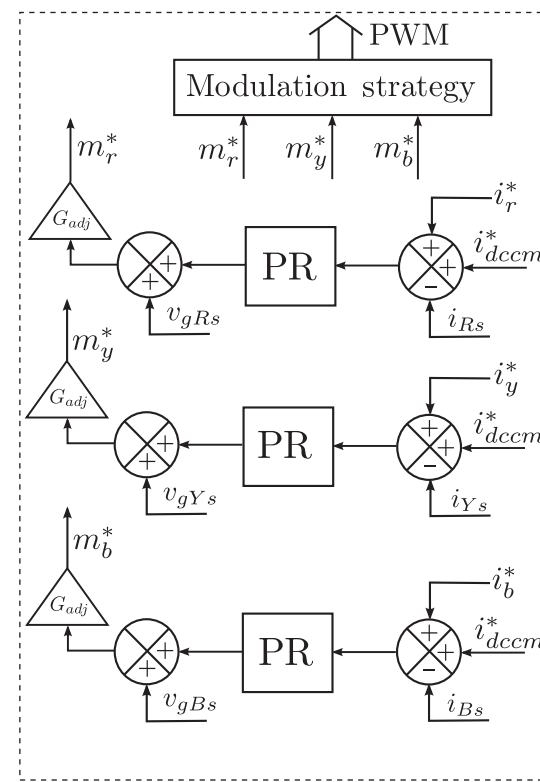

(a)

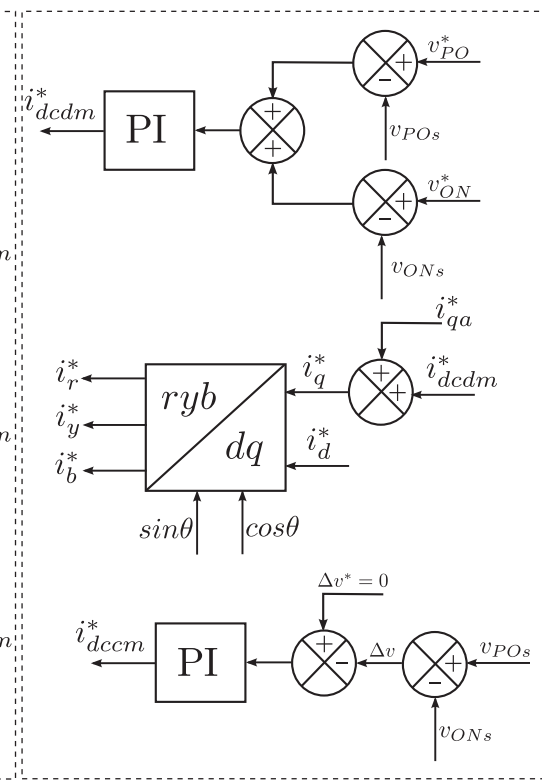

(b)

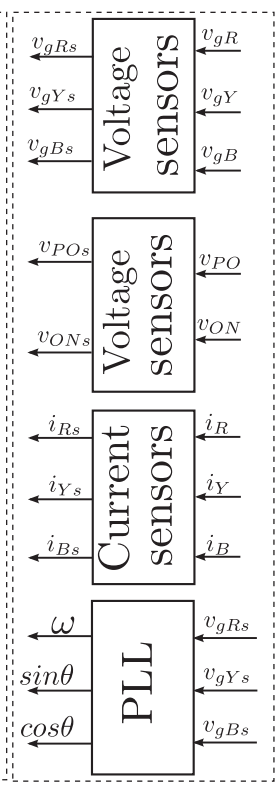

(c)

Figure 8. Controller block diagram of three phase four wire grid connected inverter. (a) Current control in natural reference frame using PR controller. (b) DC bus voltage control and reference current generation for natural reference frame. Here $i_{d c d m}^{*}$ is the differential mode component of current for total DC bus voltage control and $i_{d c c m}^{*}$ is the common mode component of current for DC bus voltage balancing control. (c) Sensing units and phase locked loop.

\subsection{System model}

In this case the two bus voltages $v_{P O}$ and $v_{N O}$ in figure 1 are sensed and the sensor gains are $K_{v}$. The sensor gain is related to base voltage by $K_{v}=\frac{1}{V_{b}}$. The summation of these two voltages gives the total dc bus voltage $v_{d c}$, shown in figure 8(b).

The dc bus side can be modelled using SRF theory and power balance on ac and dc side of the inverter (Prasad et al 2008). The PLL module is used to keep the VSI synchronized to grid. The synchronizing signals or the unit vectors are used for computations of ' $a b c$ ' frame reference current from ' $d q$ ' reference frame. These reference currents are synchronized to the grid in phase and frequency. Under synchronized condition the $d$ axis grid voltage $v_{d}=0$ and $q$ axis grid voltage $v_{q}=1.5 V_{m}$, where $V_{m}$ is the peak value of per phase grid voltage. Assuming fundamental peak of inverter terminal voltage to be $V_{i m}$, the inverter terminal voltages for $d q$ reference frame can be calculated using the unit vectors. Now for operation under any power factor, inverter terminal voltage and grid voltage have a small phase difference between them. This means that the inverter terminal voltage in ' $d q$ ' reference frame can be approximated as $v_{i d} \approx 0$ and $v_{i q} \approx 1.5 V_{i m}$. Active power on inverter terminal side can be calculated as $\frac{2}{3} v_{i q} i_{q}$ and power on dc bus side can be expressed as $v_{d c} i_{d c}$. An expression for $i_{d c}$ can be obtained, shown in (18), by equating power on ac and de side.

$$
i_{d c}=\frac{2}{3} \frac{v_{i q}}{V_{d c}} i_{q} \approx \frac{V_{i m}}{V_{d c}} i_{q} .
$$


The gain $K_{d c}=\frac{V_{i m}}{V_{d c}}$ relates $i_{d c}$ to $i_{q}$. As operating modulating index under normal operating conditions is close to unity so it can be assumed that $V_{i m} \approx \frac{V_{d c}}{2}$. Hence this gain $K_{d c} \approx 0.5$.

Here $i_{d c}$ is the current responsible for charging and discharging of dc bus capacitor $\left(C_{d}\right)$. Therefore the dc bus capacitor and voltage balancing resistors $\left(R_{d}\right)$ can be modelled in frequency domain as shown in the following equation:

$$
G_{p}^{d c}=\frac{2 R_{d}}{1+s R_{d} C_{d}}
$$

The dc bus voltage controller is the outer loop and it closes around the inner current loop. The current loop being faster in response can be approximated as a gain of $\frac{1}{K_{i}}$ for controller design of voltage loop. A PI controller has been chosen here for total dc bus voltage control. The transfer function of the PI controller for dc bus voltage control is given in the following equation:

$$
G_{c}^{d c}=K_{p}^{d c}+\frac{K_{i}^{d c}}{s}=K_{p}^{d c}\left(\frac{1+s \tau_{d c}}{s \tau_{d c}}\right) .
$$

Here $K_{i}^{d c}=\frac{K_{p}^{d c}}{\tau_{d c}}$. The input to PI controller is the difference between reference voltage $v_{d c}^{*}$ and total bus voltage $v_{d c}$. The output of PI controller can be taken as reference current $i_{q}^{*}$ which signifies the $q$ axis current reference for active power exchange. Similarly for reactive power exchange a current reference $i_{d}^{*}$ is defined. Using the unit vectors, $i_{q}^{*}$ and $i_{d}^{*}$ are converted to reference currents $i_{r}^{*}, i_{y}^{*}$ and $i_{b}^{*}$. These are the reference currents for PR controller in individual phases to control fundamental current. Now inverter terminal currents, that is $i_{r}, i_{y}$ and $i_{b}$, can also be transformed into $d q$ reference frame currents $i_{q}$ and $i_{d}$ using the unit vectors. Hence $i_{q}^{*}$ can be related to $i_{q}$ by the expression $i_{q}=\frac{i_{q}^{*}}{K_{i}}$. Using the transfer function models of individual blocks of the closed loop system shown in figure 9 , the loop gain for this system can be calculated. The loop gain $G H^{d c}(s)$ for dc bus voltage controller loop is given in the following equation:

$$
G H^{d c}(s)=K_{p}^{d c}\left(\frac{1+s \tau_{d c}}{s \tau_{d c}}\right) G_{c l}^{c c} \times K_{d c} \times \frac{2 R_{d}}{1+s R_{d} C_{d}} K_{v}
$$

This expression is used along with the desired bandwidth $\omega_{c r}^{d c}$, to design the parameters of the dc bus voltage controller.

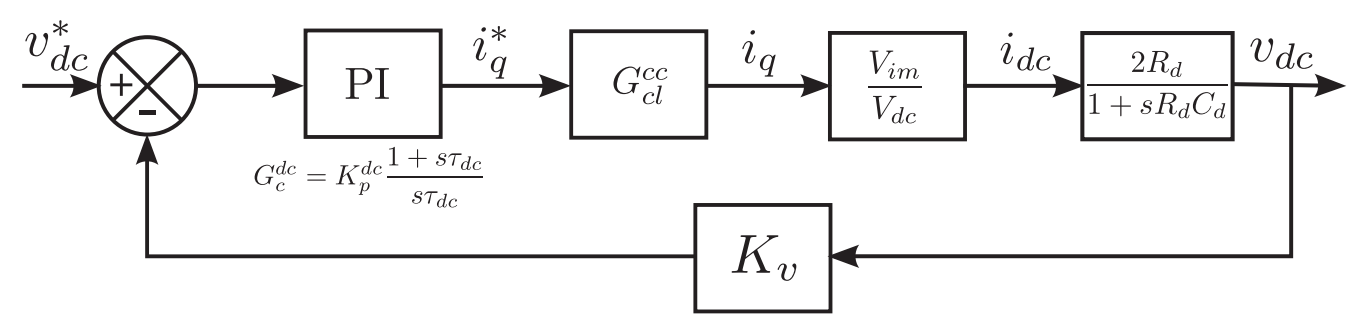

Figure 9. Block diagram representation of dc bus voltage control loop. 


\subsection{DC bus voltage controller design}

The dc bus voltage controller design requires $K_{p}^{d c}$ and $K_{i}^{d c}$ to be calculated for a chosen gain crossover frequency of $G H^{d c}(s)$. For design of the PI controller $\tau_{d c}$ can be selected as $R_{d} C_{d}$ to cancel a pole of the voltage loop. Therefore the voltage loop gain becomes $G H^{d c}(s)=\frac{K_{p}^{d c} K_{v}}{s K_{i} C_{d}}$ for $\tau_{d c}=R_{d} C_{d}$. The closed loop transfer function $G_{c l}^{d c}$ can be calculated using $G H^{d c}(s)$ and block diagram of figure 9. The expression for $G_{c l}^{d c}$ is given in the following equation

$$
G_{c l}^{d c}=\frac{1}{K_{v}} \times \frac{1}{1+s \frac{K_{i} C_{d}}{K_{p}^{d c} K_{v}} .}
$$

Value of $K_{p}^{d c}$ can be calculated for a chosen gain crossover frequency $\omega_{c r}^{d c}$ from (23) which is obtained from (22).

$$
K_{p}^{d c}=\omega_{c r}^{d c} \times \frac{K_{i} C_{d}}{K_{v}}
$$

In case the converter is operating in an unbalanced grid voltage condition then a ripple voltage would be present in the dc bus voltage. Choice of $\omega_{c r}^{d c}$ should be done considering this condition also.

\subsection{Design example}

A step by step design procedure along with an example design is given below.

- Here the gain crossover frequency of voltage loop, $\omega_{c r}^{d c}$, is selected as $62.8 \mathrm{rad} / \mathrm{s}$ or $10 \mathrm{~Hz}$. Due to unbalance and harmonic grid voltage if ripple voltage appear at fundamental or at its multiple frequency then a low $\omega_{c r}^{d c}$ should be able to provide attenuation to the ripple frequency. For the selected crossover frequency the settling time of the dc bus voltage control would be $64 \mathrm{~ms}$.

- From the design choice stated earlier $\tau_{d c}=R_{d} C_{d}$ is selected. For the chosen example $\tau_{d c}=82.5 \mathrm{~s}$.

- Value of $K_{p}^{d c}$ can be calculated using (23), chosen $\omega_{c r}^{d c}$ and parameters listed in table 1. For the chosen example $K_{p}^{d c}=6.2$.

- At this point using the designed values, a frequency response plot of $G H^{d c}(s)$ is necessary to confirm the value of gain crossover frequency and phase margin to ensure a stable system. A frequency response plot of $G H^{d c}(s)$ is given in figure 10 .

The calculated values of relevant parameters for dc bus voltage controller are tabulated in table 3 . For the chosen converter configuration apart from total dc bus controller a dc bus balancing controller is also necessary (Ghosh \& Narayanan 2008; Ghoshal \& John 2011). In this work the imbalance mitigation procedure reported in (Ghoshal \& John 2011) has been adopted. The frequency response of $G H^{d c}(s)$ has been plotted in figure 10 using $G_{c l}^{c c}$ in (21). By using $G_{c l}^{c c a}$, which is the approximation of $G_{c l}^{c c}$, in (21) frequency response plot of dc bus loop gain can also be obtained. This is termed as $G H_{a}^{d c}$ and also shown in figure 10. The low frequency region in frequency response plots of $G H^{d c}$ and $G H_{a}^{d c}$ are similar. Hence the approximated closed loop transfer function of current loop can be used for voltage controller design gains and relate it to the dc bus settling time.

The above design procedure provides the dc bus PI controller. 


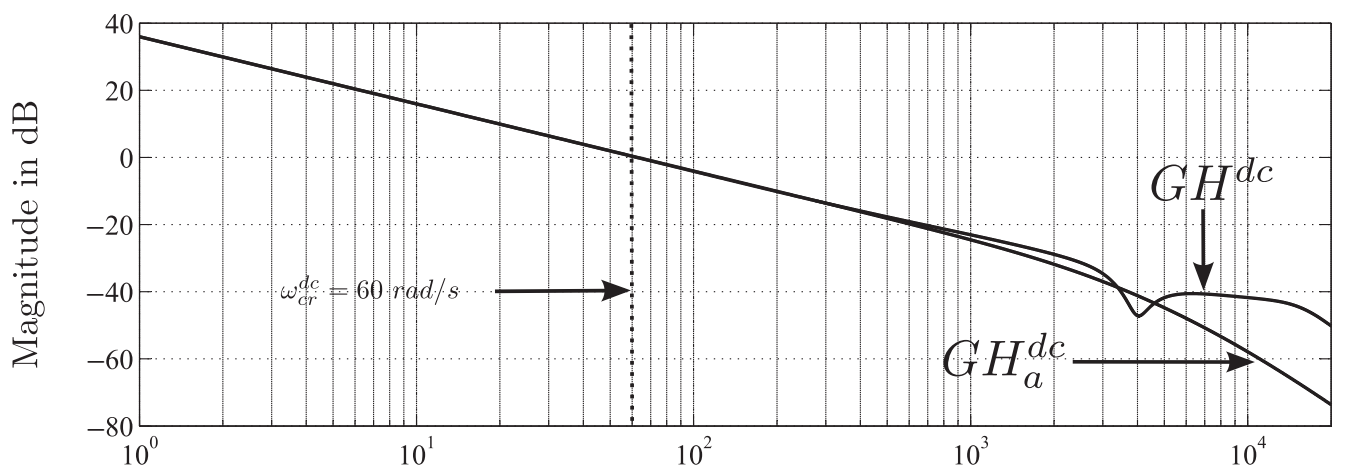

Frequency in $\mathrm{rad} / \mathrm{s}$

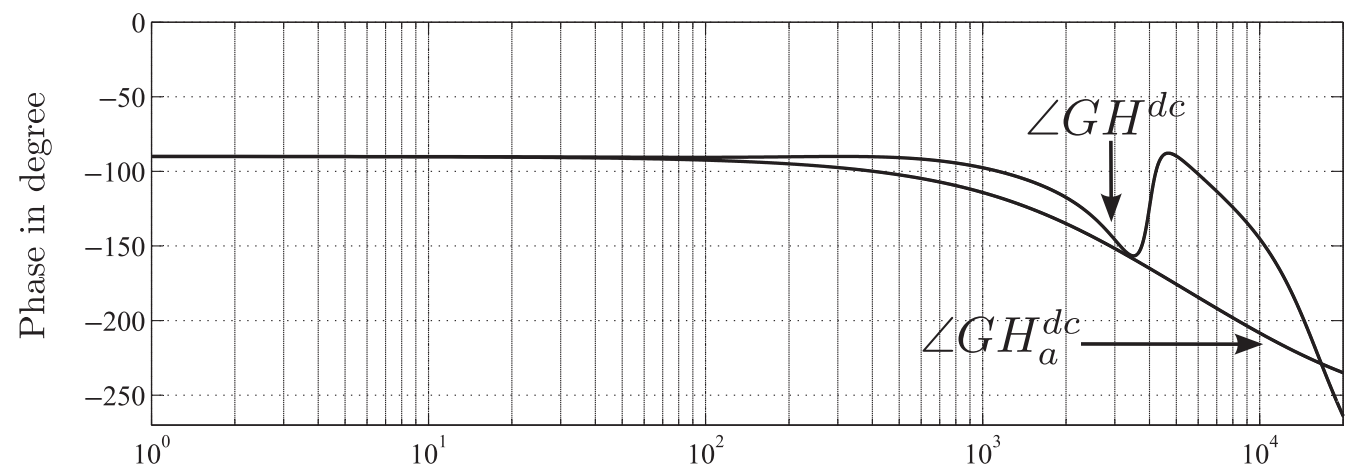

Frequency in $\mathrm{rad} / \mathrm{s}$

Figure 10. Frequency response plots of loop gain of voltage loop, $G H^{d c}(s)$, and its approximated transfer function $G H_{a}^{d c}$.

Table 3. Parameters and gains related to dc bus voltage controller.

\begin{tabular}{lcccc}
\hline $\begin{array}{l}\text { Selected crossover } \\
\text { frequency } \\
\omega_{c r}^{d c}\end{array}$ & $K_{p}^{d c}$ & $\tau_{d c}$ & $\begin{array}{c}\text { Crossover frequency } \\
\text { of } G H^{d c}(s) \\
\text { from Bode plot }\end{array}$ & $\begin{array}{c}\text { Settling } \\
\text { time }\end{array}$ \\
\hline $10 \mathrm{~Hz}$ & 6.2 & $82.5 \mathrm{~s}$ & $62.4 \mathrm{rad} / \mathrm{s}$ & $64 \mathrm{~ms}$ \\
\hline
\end{tabular}

\section{Experimental result}

The above discussed control method has been implemented in an Altera Cyclone-II FPGA board. The computation has been carried out in fixed point arithmetic format with a register size of 16 bit. The integration processes have been carried out in 32 bit format. The clock frequency of the FPGA has been $20 \mathrm{MHz}$ and the chosen sampling frequency is $50 \mu \mathrm{s}$.

During experiment, the dc bus voltage has been kept at $300 \mathrm{~V}$. Grid voltage and current waveform for steady state operation of the VSI as a STATCOM are shown in figure 11. The inverter current controller tracks the inverter current command accurately. Distortions in the grid side currents are due to harmonics in the grid voltages and its interactions with the LCL filter. The transient response study on current controller is shown in figure 12(a). The reference current has 


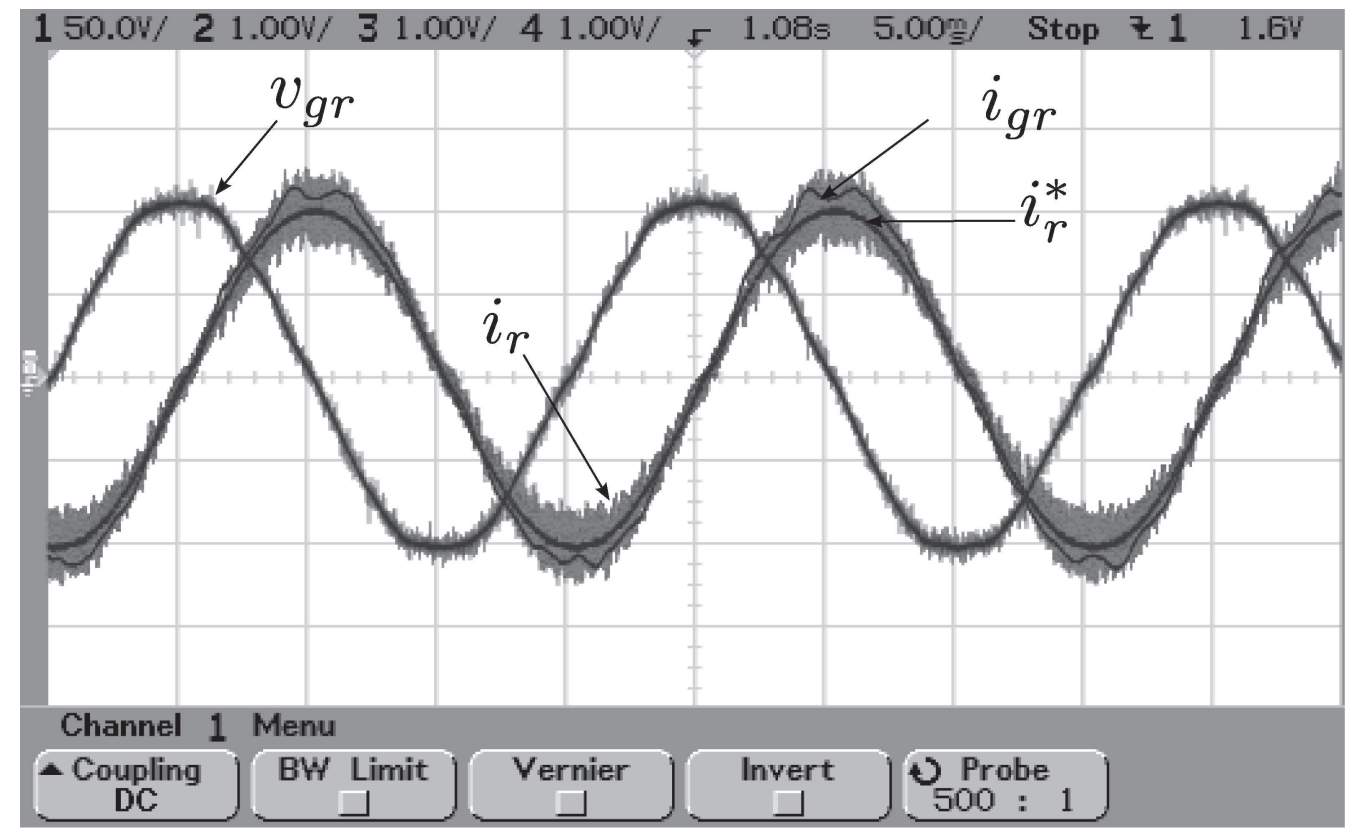

Figure 11. Grid voltage $\left(v_{g r}\right)$, 'R' phase VSI side inductor current $\left(i_{r}\right)$ and reference current $\left(i_{r}^{*}\right)$ and 'R' phase grid side inductor current $\left(i_{g r}\right)$ at steady state condition during operation as a STATCOM. Scale: $\mathrm{X}$-axis: $5 \mathrm{~ms} / \mathrm{div}$ and Y-axis: $\mathrm{Ch} 1 \rightarrow 90 \mathrm{~V} / \mathrm{div}$; $\mathrm{Ch} 2, \mathrm{Ch} 3$ and $\mathrm{Ch} 4 \rightarrow 3 \mathrm{~A} / \mathrm{div}$.

been set to 5 A peak. The settling time for current controller can be observed from figure 12(a), where only $\mathrm{R}$ phase current $i_{r}$ and its reference value $i_{r}^{*}$ are shown. The settling time can be observed to be $1.5 \mathrm{~ms}$ approximately. This is close to the designed value of $1.33 \mathrm{~ms}$ calculated in subsection 3.4.

A step change of $20 \mathrm{~V}$ has been applied to total dc bus reference $v_{d c}^{*}$, where $v_{d c}^{*}=v_{P O}^{*}-$ $v_{N O}^{*}$, for observing the transient performance of DC bus voltage controller. The result, shown in figure 12(b), shows a settling time of nearly $60 \mathrm{~ms}$ which is close to designed value of $64 \mathrm{~ms}$.

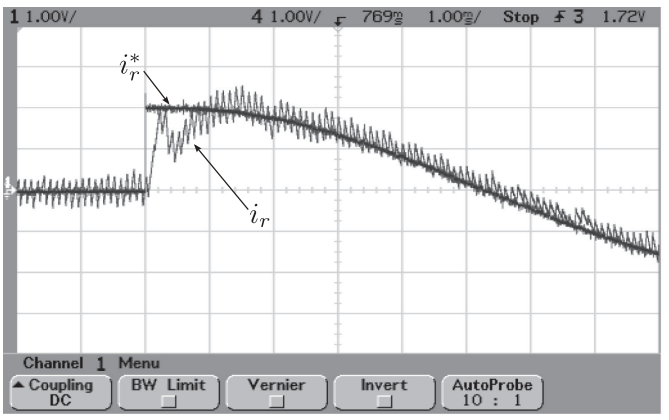

(a)

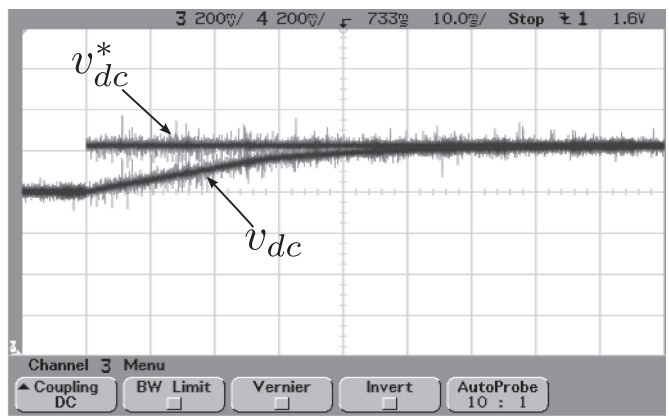

(b)

Figure 12. (a) Transient response performance of current controller. Scale: $X$-axis: $1 \mathrm{~ms} / \mathrm{div}$ and $Y$-axis: 3 A/div. (b) Transient response performance of voltage controller. Scale: X-axis: $20 \mathrm{~ms} / \mathrm{div}$ and Y-axis: $45 \mathrm{~V} /$ div. 


\section{Conclusion}

In this work closed loop operation of a 3 phase 4 wire VSI with LCL filter has been analysed in a simplified manner to obtain closed form expressions for controller gains. An asymptotic frequency response plot basis design method for this higher order system and desired gain bandwidth has been utilised for this purpose. The closed loop control architecture consists of a inner current loop and two outer dc bus voltage controller loops. The inner current loop has been implemented using a PR controller in a per phase manner in stationary 'abc' reference frame. Using the asymptotic analysis method the higher order current loop response has been approximated to a first order system. The simplified system has been utilised further to analyse and design the dc bus voltage control loop. The dc bus controller needs total bus voltage control and imbalance control as the neutral of grid is connected to dc bus midpoint. The analysed system response in time domain has been verified through experiments. Matching experimental results have been presented in support of the adopted controller design method.

\section{References}

Bao X, Zhuo F, Tian Y and Tan P 2013 Simplified feedback linearization control of three phase photovoltaic inverter with an LCL filter. IEEE Trans. Power Electron. 28(6): 2739-2752

Blaabjerg F and Pedersen J K 1997 A new low-cost, fully fault-protected PWM-VSI inverter with true phase current information. IEEE Trans. Power Electron. 12(1): 187-197

Blaabjerg F, Teodorescu R, Liserre M and Timbus A V 2006 Overview of control and grid synchronization for distributed power generation systems. IEEE Trans. Ind. Electron. 53(5): 1398-1409

Channegowda P and John V 2010 Filter optimization for grid interactive voltage source inverters. IEEE Trans. Ind. Electron. 57(12): 4106-4114

Engelberg S 2005 A mathematical introduction to control theory. Imperial College Press

Gabe I, Montagner V and Pinheiro H 2009 Design and implementation of a robust current controller for VSI connected to the grid through an LCL filter. IEEE Trans. Power Electron. 24(6): 1444-1452

Ghosh R and Narayanan G 2008 Control of three phase, four wire PWM rectifier. IEEE Trans. Power Electron. 23(1): 96-106

Ghoshal A and John V 2011 DC bus imbalance compensation in a three phase four wire grid connected inverter. In: Proc. Nat. Power Electron. Conf., Shibpur, India

Harnefors L 2009 Implementation of resonant controllers and filters in fixed point arithmetic. IEEE Trans. Ind. Electron. 56(4): 1273-1281

Holmes D G, Lipo T A, McGrath B P and Kong W Y 2009 Optimized design of stationary frame three phase AC current regulators. IEEE Trans. Power Electron. 24(11): 2417-2426

Limongi L, Bojoi R, Griva G and Tenconi A 2009 Digital current control schemes. IEEE Ind. Electron. Mag. 3(1): 20-31

Loh P C and Holmes D G 2005 Analysis of multiloop control strategies for LC/CL/LCL filtered voltage source and current source inverters. IEEE Trans. Ind. Appl. 41(2): 644-654

McGrath B, Parker S and Holmes D 2013 High performance current regulation for low pulse ratio inverters. IEEE Trans. Ind. Appl. 49(1): 149-158

Prasad J S S, Bhavsar T, Ghosh R and Narayanan G 2008 Vector control of three phase AC/DC front end converter. Academy Proc. Eng. Sci., Sadhana 33(5): 591-613

Shen G, Zhu X, Zhang J and Xu D 2010 A new feedback method for PR current control of LCL filter based grid connected inverter. IEEE Trans. Ind. Electron. 57(6): 2033-2041

Tang Y, Loh P C, Wang P, Choo F H, Gao F and Blaabjerg F 2012 Generalized design of high performance shunt active power filter with output LCL filter. IEEE Trans. Ind. Electron. 59(3): 1443-1452

Teodorescu R, Blaabjerg F, Liserre M and Dell Aquila A 2003 A stable three phase LCL filter based active rectifier without damping. In: 38th IAS Annu. Meeting., Ind. Appl. Conf. 2003, 3: 1552-1557 
Teodorescu R, Blaabjerg F, Liserre M and Loh P C 2006 Proportional resonant controllers and filters for grid connected voltage source converters. Proc. Inst. Elect. Eng., Electric Power Appl. 153(5): 750-762

Yepes A, Freijedo F, Doval-Gandoy J, Lopez O, Malvar J and Fernandez-Comesana P 2010 Effects of discretization methods on the performance of resonant controllers. IEEE Trans. Power. Electron. 25(7): $1692-1712$

Yepes A, Freijedo F, Lopez O and Doval-Gandoy J 2011 Analysis and design of resonant current controllers for voltage source converters by means of nyquist diagrams and sensitivity function. IEEE Trans. Ind. Electron. 58(11): 5231-5250

Yuan X, Merk W, Stemmler H and Allmeling J 2002 Stationary-frame generalized integrators for current control of active power filters with zero steady state error for current harmonics of concern under unbalanced and distorted operating conditions. IEEE Trans. Ind. Appl. 38(2): 523-532

Zmood D N and Holmes D G 2003 Stationary frame current regulation of PWM inverters with zero steady state error. IEEE Trans. Power Electron. 18(3): 814-822 